\title{
Clinicopathological and immunological studies on Toxoid vaccine as a successful alternative in controlling clostridial infection in broilers
}

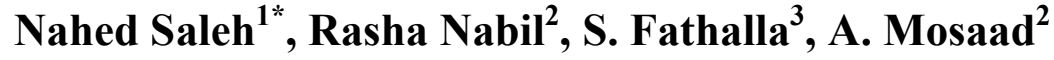 \\ ${ }^{1}$ Department of Clinical Pathology, ${ }^{2}$ Department of Bacteriology, Mycology and Immunology and ${ }^{3}$ \\ Department of Physiology, Faculty of Veterinary Medicine, Menufiya University, El-Sadat Branch, \\ Egypt.
}

Three vaccination regimes based on Clostridium perfringens ( $C$. perfringens) type $\mathrm{A}, \mathrm{C}$ or combined AC toxoids were evaluated to detect if toxoid vaccines can prevent necrtotic enteritis (NE) caused by clostridial infection in broilers. The vaccines were administered two times at two weeks interval, then the birds were challenged with virulent strains of $C$. perfringens type $\mathrm{A}, \mathrm{C}$ or combined AC. Blood samples were taken after both first and second vaccination doses as well as after challenge. Evaluating parameters included clinical signs, gross intestinal lesions, hemogram [red blood cell count (RBCs), packed cell volume (PCV), hemoglobin (Hb), total leukocytic count (TLC) and differential leukocytic count],serum biochemical assays [total protein (TP), albumin (Alb), globulin (Glob), albumin globulin ratio (A/G), serum activities of alanine amino transferase (ALT), aspartate amino transferase (AST), alkaline phosphatase (ALP) and uric acid (UA) values] and ELISA test for detecting serum antibody titers. Results revealed that affected birds showed marked depression, anorexia, reluctance to move, ruffled feathers and diarrhea. Numbers of chickens with intestinal lesions in immunized challenged groups were greatly fewer than the infected non immunized ones. There was an increase in RBCs, PCV and Hb. TLC decreased in infected non immunized birds and increased in vaccinated ones. Heterophils were increased in infected groups while, lymphocytes decreased. Prominent lymphocytosis was observed in immunized birds. Results of biochemical assays showed that there was a significant increase in TP, Alb, Glob, ALP, ALT, AST and UA and decrease in A/G. Results of ELISA test showed that there was a significant increase in antibody titer after immunization paricularly after the second dose of vaccination. The combined $\mathrm{AC}$ toxoid provided the greater antibody titer and best protection followed by toxoid $\mathrm{A}$ and finally toxoid $\mathrm{C}$. We concluded that results provide an evidence that immunization of broilers with toxoid vaccines paricularly the combined type $\mathrm{AC}$ is safe, welltolerated and can protect broiler chickens against $\mathrm{NE}$ after the second booster dose of the vaccine.

Clostridia perfringens (C. perfringens) are spore-forming bacteria that can be found anywhere. They are present in the soil, litter, feed, intestine and droppings of all animals, but they are more commonly isolated in large numbers in broiler houses. Clostridia in low numbers are normal inhabitants of all animal as well as chicken intestines with no apparent impact on the host (Niilo, 1980; Ficken and Wages, 1997). Under certain circumstances, the organism causes a spectrum of illness, which includes subclinical disease, mild clinical infection including diarrhea, as well as the more commonly recognized fulminant disease, necrotic enteritis (NE), one of the most economically important enteric diseases in broiler chickens that can result in outbreaks with substantial mortality based upon identification of

\footnotetext{
* Corresponding author. Tel.: +20 048/2603215; Fax: +20 048/2603214

E-mail address: nahedsaleh2001@yahoo.com (Nahed Saleh)
}

the organism in field cases (Parish, 1961; Kaldhusdal and Hofshagen, 1992; Kaldhusdal and Lovland, 2000; Lovland and Kaldhusdal, 2001; Van Immerseel et al., 2004). The standard approach in the poultry industry to protect against this disease is through the use of antibiotic feed additives that have been used to control the disease for many years (McReynolds et al., 2004). As the poultry industry has moved to minimize the use of antibiotics, the incidence of NE has increased creating an urgent need for other methods of control as vaccines (Connolly,2001; Kulkerni et al., 2006; Thompson et al., 2006, Broussard et al., 2008; Gobbi, 2008). Based on strong scientific evidence and extensive experience with clostridial vaccines for other animals, some recent studies have been carried out on $C$. perfringens type A toxoid (Heier et al., 2001; Kulkarni et al., 2007; Broussard et al., 2008; Gobbi, 2008; Newman and Ambrose, 2008) or 
C. perfringens type A and C toxoid (Lovland et al., 2004) and have shown promising results.

The purpose of this paper is to evaluate the currently recognized vaccination regimes of toxoid in controlling the NE in broilers based on $C$. perfringens type $\mathrm{A}, \mathrm{C}$ and combined $\mathrm{AC}$ toxoid with particular emphasis is placed on clinicopathological and immunological changes associated with these vaccination regimes.

\section{Materials and methods}

Birds. A total of 175 one day old commercial Ross 208 broiler chickens obtained from ElWadi Company for chicken production at Sadat city were used in this experiment. Birds were kept on floors covered with wood shavings and fed a balanced ration till the end of experiment.

Isolation of $\boldsymbol{C}$. perfringens strains. Two toxin producing $C$. perfringens strains $\mathrm{A}$ and $\mathrm{C}$ were isolated from cases of clinical NE local chickens. The isolates were fully identified by the Department of Bacteriology, Mycology and Immunology at the Faculty of Veterinary Medicine Menufiya University. The diagnosis was confirmed by Polymerase Chain Reaction (PCR).

Preparation of toxoid vaccines. Toxoid vaccines were prepared by adding formalin 0.3 $\%$ to the previously prepared clostridial toxins A and $\mathrm{C}$, incubated at $37^{\circ} \mathrm{C}$ and checked daily for 3 days. The solutions then were centrifuged at $5000 \mathrm{rpm}$ for 5 minutes and the supernatants were used as toxoid vaccines A and C. Complete detoxification was regarded when $0.2 \mathrm{ml}$ of toxoid was injected intravenously into mice and the mice survived after 8 hours (Gadalla et al., 1969).

Experimental Groups and protocol. The birds were classified into seven groups of chicken each of 25. Primarily, the experiment started with four groups. At seven days old, three groups of birds were vaccinated with toxoid $\mathrm{A}$ (TA), toxoid C (TC) and combined toxoid AC (TAC) at a dose of $0.5 \mathrm{ml}$ subcutaneously. The fourth group was kept as a control negative (C ve). All groups were kept under observation and were protected by vaccination program against viral diseases such as Newcastle and Gumboro virus diseases. Two weeks later (at 21 days old), the three previously mentioned immunized groups were given a second booster dose of vaccines at the same dose rate.

Challenge of the immunized chickens. Two weeks following the second vaccination dose, all immunized birds were challenged with virulent strains of $C$. perfringens type A (Ch A), C (Ch
C) or $\mathrm{AC}(\mathrm{Ch} \mathrm{AC})$ [Thioglycolate broth media containing $\log 10 \mathrm{CFU} / \mathrm{ml}$ (colony forming unit) of $C$. perfringens was mixed with feed at a ratio of 2:1 (2 liters of fluid media/1 Kg food) or the fluid was added to drinking water at a ratio of 1:2 (1 liter of fluid media/2 liters water)) for 3 successive days. At this stage of experiment, another 3 groups of non immunized birds each of 25 were infected also by virulent strains of $C$. perfringens type $\mathrm{A}, \mathrm{C}$ or $\mathrm{AC}$ in the same way as immunized groups and considered as control positive $(\mathrm{C}+\mathrm{ve} \mathrm{A}, \mathrm{C}+\mathrm{ve} \mathrm{C}$ and $\mathrm{C}+\mathrm{ve} \mathrm{AC}$; respectively).

Blood samples. Blood samples were collected three times, 2 weeks following the first vaccination dose, 2 weeks following the second vaccination dose and finally three days after challenge.

All blood samples were classified into two parts, the first blood samples were placed in tubes containing sodium ethylenediamine tetraacetic acid (EDTA) for the hematological assays, whereas the second blood samples were placed into plane tubes, left for 30 minutes then centrifuged for serum separation. Serum samples were stored at $-20^{\circ} \mathrm{C}$ until assayed for ELISA and other biochemical tests.

\section{Parameters evaluated.}

Clinical signs and gross pathological lesions. Birds were observed for any abnormal clinical signs. The small intestine and liver were examined for gross visible lesions. The intestinal lesions were scored as 0 (no lesion), 1 (thin or friable wall), 2 (focal necrosis or ulceration), 3 (large necrotic patches) and 4 (severe extensive necrosis).

Clinical pathology. The assays included the hemogram [red blood cell count (RBCs), packed cell volume (PCV), hemoglobin $(\mathrm{Hb})$, total leukocytic count (TLC) and differential leukocytic count] and the serum biochemical assays [total protein (TP), albumin (Alb), globulin (Glob), albumin globulin ratio (A/G), serum activities of alanine amino transferase (ALT), aspartate amino transferase (AST) and alkaline phosphatase (ALP) and serum uric acid (UA) values].

ELISA tests. Serum samples were analyzed for determination of antibody levels using ELISA technique. The optical densities were read at 405 $\mathrm{nm}$ with a micro-ELISA reader system. The sera were considered positive when the absorbance values were as or more than the cut off value (the cut off value $=$ double of the mean of negative sera). 
Statistical analysis. Data were subjected to statistical analysis using one way analysis of variance (ANOVA). Means were compared by the Duncan test at 0.05 level of probability. Differences at $p<0.05$ were considered significant. All data were presented as mean \pm standard deviation (SD).

\section{Results}

Clinical signs and gross lesions. Affected birds showed marked depression, anorexia, reluctance to move, ruffled feathers, drooping wings and head in addition to diarrhea. The birds gradually became dehydrated and emit a foul smell. Immunized groups showed similar but very mild symptoms. No deaths occurred among chickens of any group along the whole experimental period. Gross lesions generally occur in the small intestine, in particular in the jejunum and ileum. Gross lesions included focal to large necrotic patches with no hemorrhage. Results of the intestinal lesion scores are shown in (table 1) and revealed that challenged immunized groups had significantly fewer numbers of chickens with intestinal lesions in all score divisions particularly in the group immunized with combined $\mathrm{AC}$ toxoid followed by toxoid $\mathrm{A}$ and then toxoid C (Fig. 1). No gross lesions were detected in the liver or other internal organs.

Hematology. Results of hematological tests are shown in (table 2). RBCs and PCV values significantly increased particularly in $\mathrm{C}+\mathrm{ve}$ groups infected with $C$. perfringens type $\mathrm{C}$ and $\mathrm{AC}$, in addition to challenged groups. The increase was less prominent in immunized groups. Significant increases in $\mathrm{Hb}$ concentration were observed in the $\mathrm{C}+\mathrm{ve}$ groups. Immunized groups showed decrease in $\mathrm{Hb}$ levels and challenge did not result in significant changes in $\mathrm{Hb}$ concentration.

TLC was decreased in $\mathrm{C}+\mathrm{ve}$ groups and increased in challenged and immunized groups particularly in association with the second dose of vaccination.

Results of differential leukocytic count shown in (table 2) revealed that heterophil's percentage significantly increased in all treated groups specially in the $\mathrm{C}+\mathrm{ve}$ ones. With the second dose of toxoid AC, heterophils were slightly decreased. Lymphocyte's percentage significantly decreased in $\mathrm{C}+\mathrm{ve}$ groups and significantly increased in immunized ones. The increase was more pronounced after the second dose of vaccination. In challenged immunized groups, lymphocytes were significantly decreased but to a lesser extent than $\mathrm{C}+\mathrm{ve}$ groups.

Monocytes did not change significantly in $\mathrm{C}$ $+v e$ and challenged groups. On the other hand monocytes were decreased significantly in association with both vaccination doses of toxoid AC. Eosinophils were significantly decreased in $\mathrm{C}+\mathrm{ve} \mathrm{A}$ and $\mathrm{AC}$ groups in addition to both vaccination doses of toxoid AC. In other groups, eosinophils did not show significant changes. Basophils were decreased in all treated groups.

Blood chemistry. As shown in (table 3), significant increase in total protein was observed in $\mathrm{C}+\mathrm{ve}$ groups as well as all immunized groups particularly in association with the booster doses. On the other hand challenging of vaccinated groups with virulent strains of $C$. perfringens type $\mathrm{A}, \mathrm{C}$ and $\mathrm{AC}$ was associated with significant decrease in the total protein concentration. Alb levels increased particularly in $\mathrm{C}+\mathrm{ve}$ groups. Significant increase in Glob concentration was recorded in all treated groups specially in the immunized chickens particularly after the second dose of vaccination to be decreased again in the challenged groups.

$\mathrm{A} / \mathrm{G}$ ratio was decreased in immunized groups and did not show significant changes in $\mathrm{C}+\mathrm{ve}$ groups. After challenge $\mathrm{A} / \mathrm{G}$ ratio was increased in groups challenged with of $C$. perfringens type $\mathrm{A}$ and $\mathrm{AC}$.

Serum ALT showed significant increase in $\mathrm{AC}$ immunized group and in $\mathrm{C}+\mathrm{ve} \mathrm{A}$ group. No significant changes in serum AST were seen in immunized broilers while activities were increased in $\mathrm{C}+\mathrm{ve}$ and challenged groups. Serum ALP significantly increased in all treated groups. Serum UA levels significantly increased mostly in toxoid AC immunized group.

Results of ELISA test. Results of ELISA test for evaluation of antibody levels are shown in (table 4). The results revealed that there was a gradual increase in the optical density values in the immunized and challenged groups particularly after the second dose of vaccination. Combined toxoid AC gave the greatest antibody levels followed by toxoid A and finally toxoid $\mathrm{C}$ (Fig. 2). 
Table (1): Intestinal lesion scores in broilers infected with $C$. perfringens type $\mathrm{A}, \mathrm{C}$ and combined $\mathrm{AC}$ compared to their corresponding immunized challenged groups (Fisher's test, $P=0.05$ ).

\begin{tabular}{lccccccc}
\hline \multirow{2}{*}{ Group } & $\begin{array}{c}\text { No. of examined } \\
\text { chicken }\end{array}$ & \multicolumn{3}{c}{ Intestinal lesion scores } & $\begin{array}{c}\text { Mean No. of chickens with } \\
\text { intestinal lesions }\end{array}$ \\
\cline { 2 - 7 } & & $\mathbf{0}$ & $\mathbf{1}$ & $\mathbf{2}$ & $\mathbf{3}$ & $\mathbf{4}$ & 0.86 \\
\hline C +ve A & 15 & 2 & 8 & 5 & 0 & 0 & 0.73 \\
C +ve C & 15 & 4 & 7 & 4 & 0 & 0 & 0.93 \\
C +ve AC & 15 & 1 & 6 & 7 & 1 & 0 & 0.24 \\
Ch A & 25 & 19 & 5 & 1 & 0 & 0 & 0.36 \\
Ch C & 25 & 17 & 6 & 2 & 1 & 0 & 0.16 \\
Ch AC & 25 & 21 & 4 & 0 & 0 & 0 & 0.86 \\
\hline
\end{tabular}

$0=$ No lesion $\quad 1=$ Thin or friable wall $2=$ Focal necrosis or ulceration $3=$ Large necrotic patches $4=$ Severe extensive necrosis

$\mathrm{C}+\mathrm{ve} \mathrm{A}=$ Non immunized group infected with virulent strain of $\mathrm{C}$. perfringens type A.

$\mathrm{C}+\mathrm{ve} \mathrm{C}=$ Non immunized group infected with virulent strain of $C$. perfringens type $\mathrm{C}$.

$\mathrm{C}+\mathrm{ve} \mathrm{AC}=$ Non immunized group infected with virulent strain of $C$. perfringens type $\mathrm{AC}$.

$\mathrm{Ch} \mathrm{A}=$ Group immunized with type A toxoid, then challenged with virulent strain of $C$. perfringens type A.

$\mathrm{Ch} \mathrm{C}=$ Group immunized with type $\mathrm{C}$ toxoid, then challenged with virulent strain of $C$. perfringens type $\mathrm{C}$.

$\mathrm{Ch} \mathrm{AC}=$ Group immunized with combined $\mathrm{AC}$ toxoid, then challenged with virulent strain of $C$. perfringens type AC.

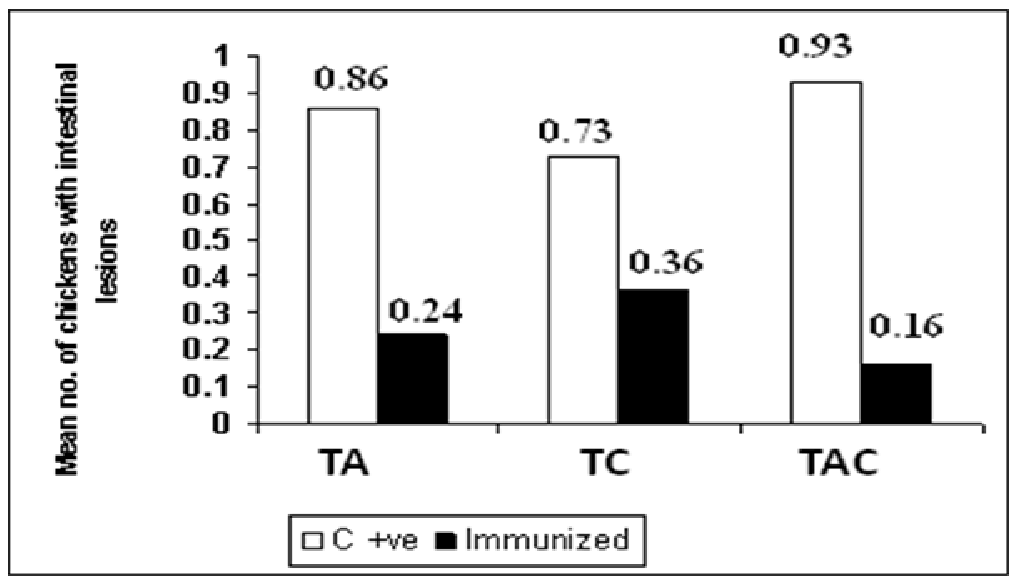

Fig. (1): Mean numbers of chickens with intestinal lesion scores in broilers infected with $\mathrm{C}$. perfringens type A (TA), C (TC) and combined AC (TAC) compared to their corresponding immunized challenged groups (Fisher's test, $p=0.05$ ).

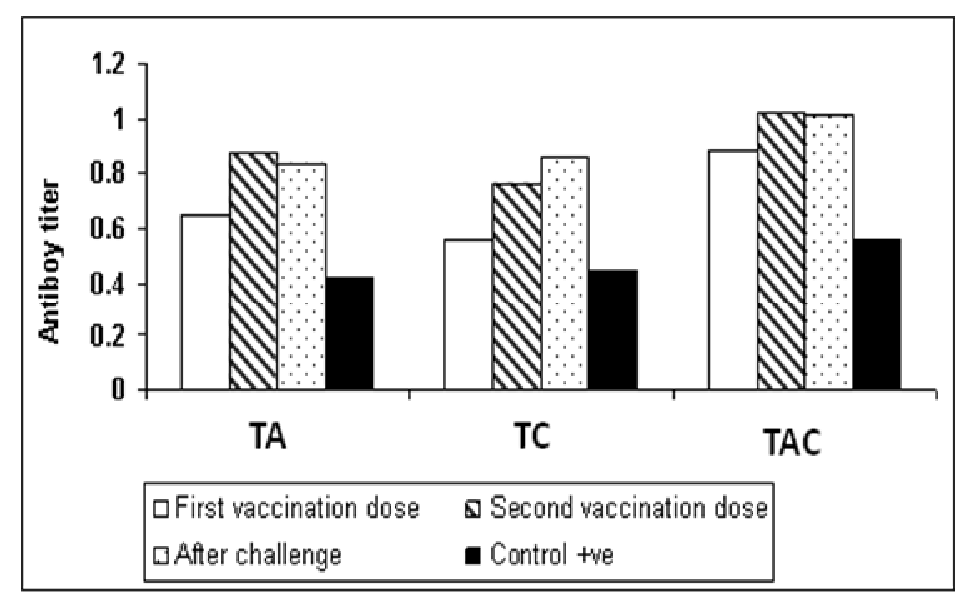

Fig. (2): The antibody titer in sera of broilers vaccinated with first and secondbooster doses of toxoid A (TA), C (TC) and combined AC (TAC) compared to their corresponding control positive and immunized challenged groups using ELISA technique (read method is read and eject, single wave length is 405) 



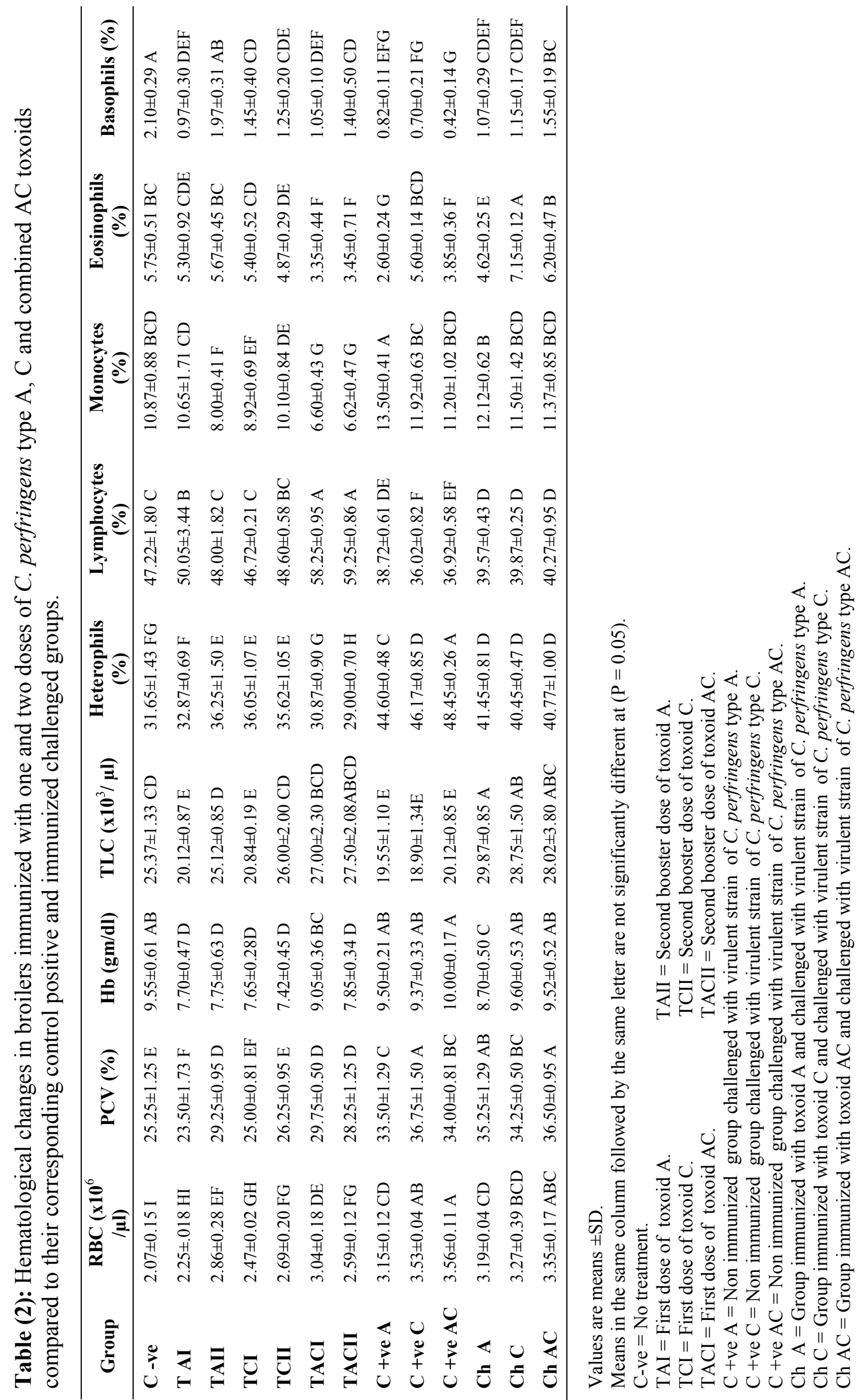



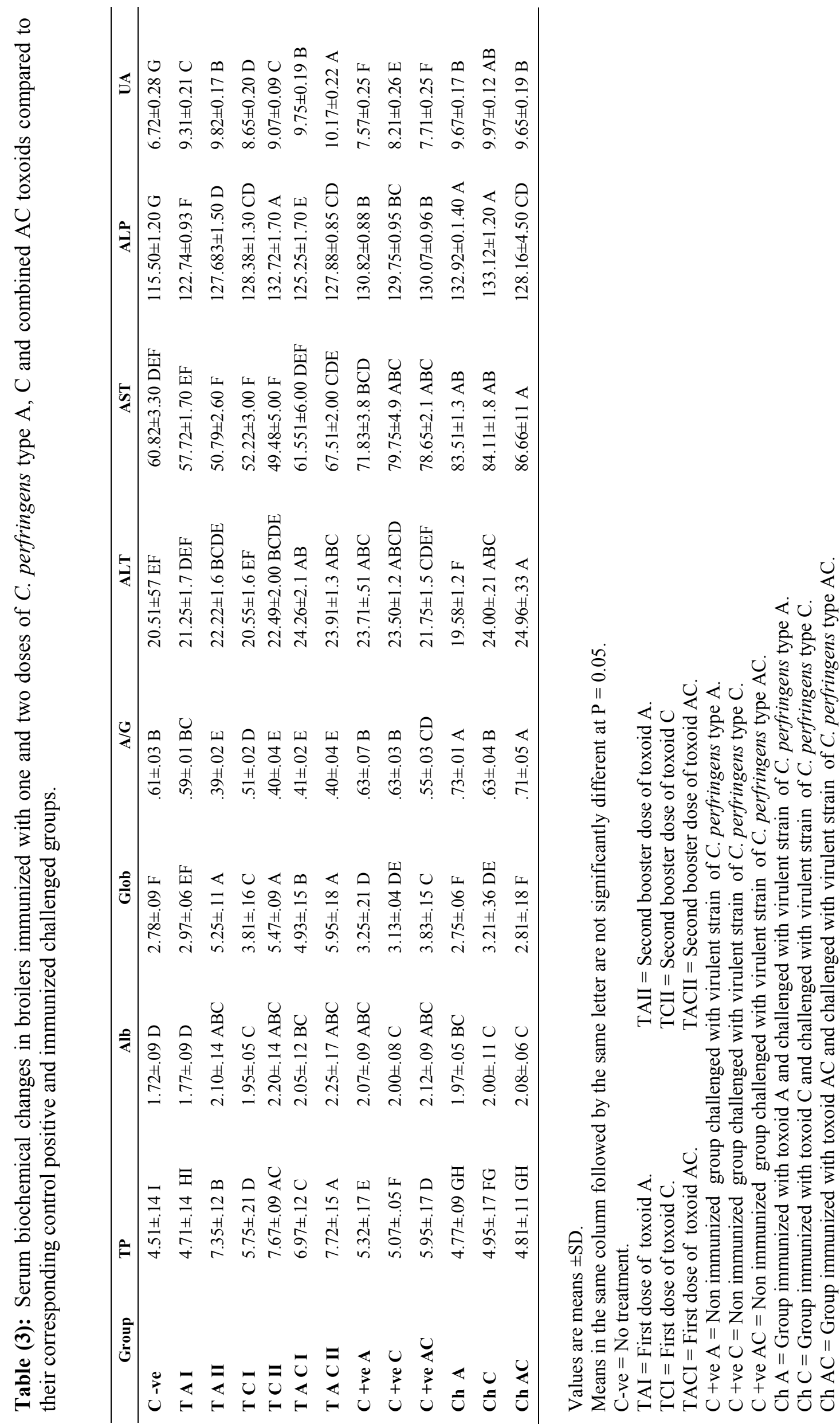
Table (4): The antibody titer in sera of broilers immunized with one and two doses of toxoid A (TA), $\mathrm{C}$ (TC) and combined AC (TAC) compared to their corresponding control positive and immunized challenged groups using ELISA technique (read method is read and eject, single wave length is 405).

\begin{tabular}{lcccc}
\hline Type of toxoid & 1st vaccination dose & 2nd vaccination dose & After challenge & Control +ve \\
\hline T A & $0.648 \pm 0.11 \mathrm{Bb}$ & $0.875 \pm 0.09 \mathrm{Ba}$ & $0.838 \pm 0.10 \mathrm{Ba}$ & $0.425 \pm 0.10 \mathrm{Bc}$ \\
$\mathrm{T} \mathrm{C}$ & $0.556 \pm 0.08 \mathrm{Cc}$ & $0.765 \pm 0.11 \mathrm{Cb}$ & $0.861 \pm 0.03 \mathrm{Ba}$ & $0.443 \pm 0.14 \mathrm{Bd}$ \\
$\mathrm{T} \mathrm{AC}$ & $0.885 \pm 0.13 \mathrm{Ab}$ & $1.019 \pm 0.16 \mathrm{Aa}$ & $1.015 \pm 0.09 \mathrm{Aa}$ & $0.556 \pm 0.18 \mathrm{Ac}$ \\
\hline
\end{tabular}

Values are means \pm SD.

Means in the same column followed by the same capital letter are not significantly different at $p=0.05$.

Means in the same row followed by the same small letter are not significantly different at $\mathrm{p}=0.05$.

\section{Discussion}

C. perfringens is a Gram-positive anaerobic bacterium that is widespread in the environment and commonly in low numbers are normal inhabitants of all animal intestines. Under certain circumstances it becomes pathogenic. It is certainly the most serious cause of clostridial enteric disease in domestic animals and broilers (Al-Sheikhly and Al-Saieg, 1980; Kaldhusdal and Lovland, 2000; Lovland and Kaldhusdal, 2001 and Van Immerseel et al., 2004). C. perfringens is now recognized as causing a spectrum of effects including subclinical infection, mild disease with focal intestinal necrosis, diarrheal illness and liver disease. This is in addition to the classic form of acute fulminant necrotizing enteritis which results in depression of the flock growth rate and high economic losses (Ficken and Wages, 1997; Kaldhusdal and Lovland, 2000 and van der Sluis, 2000). Since NE became a serious threat to poultry health and a major concern for companies that produce antibiotic free birds, it is therefore essential to investigate methods of prevention that include minimizing exposure to known risk factors and vaccination.

The present paper was designed to evaluate if the toxoid vaccine could protect birds from exposure to NE. Our results are consistent with the previous reports in that vaccination of broilers with toxoid vaccines provide greater protection in the face of NE (Heier et al., 2001; Jayappa et al., 2005 and Schrader et al., 2008). Examination of birds at necropsy revealed gross intestinal lesion scores (table 1) generally ranged from focal to large necrotic patches with no hemorrhage. The classical fulminant severe form of NE was not seen in the present study. Many factors may influence the severity of the disease associated with enteric pathogens, including virulence, host susceptibility, immune status, diet and the most important known predisposing factor for NE, the coccidial pathogens (AlSheikhly and Al-Saieg, 1980; Riddell and Kong, 1992). In the present study Coccidial infection was not detected in any smears of colorectal contents from all birds.

In birds previously immunized then challenged by the organism, fewer numbers of chickens with intestinal lesions were recorded in all score divisions supporting that vaccination reduces lesions and protects intestinal integrity in broilers. Lovland et al., (2004) demonstrated that Chicks from hens vaccinated with $C$. perfringens type A toxoid had significantly lower NE lesion scores compared to unvaccinated birds. Gobbi (2008) found that NE lesions were not observed in any of the broilers from hens vaccinated with $C$. perfringens type A toxoid.

No gross hepatic lesions were observed in the present work. This is in agreement with some reports stated that although hepatic lesions have been described in birds with both classical and mild forms of $C$. perfringens infection, most cases of hepatic lesions were detected in the more classical and severe form of $\mathrm{NE}$ (Hemboldt,1971; Hutchison and Riddell, 1990; Onderka et al., 1990 and Lovland and Kaldhusdal, 1999).

The hematological results presented in this study revealed that there was an increase in RBCs, PCV and $\mathrm{Hb}$ particularly in the $\mathrm{C}+\mathrm{ve}$ groups. This is probably due to hemoconcentration due to diarrhea that could result from a combination of fluid loss from localized inflammation and decreased fluid absorption due to disruption of the intestinal epithelial barrier (Kaldhusdal and Hofshagen, 1992; Barker et al., 1993 and McClane, 2001). Total leukocytic count decreased in $\mathrm{C}+\mathrm{ve}$ groups may be due to lymphopenia seen in these 
groups. On the other hand TLC increased in immunized groups specially in association with the second dose of vaccination may be due to the pronounced lymphocytosis in response to vaccination. Lymphopenia occurred in $\mathrm{C}+\mathrm{ve}$ groups while lymphocytosis was seen in immunized birds. Lymphopenia is usually seen in acute bacterial infections due to trapping of lymphocytes in lymph nodes (Campbell, 2004a). Stress associated with systemic illness is most commonly associated with redistribution of lymphocytes and thus lymphopenia (Campbell, 2004a). In immunized groups lymphocytosis was observed due to enhancement of the B cell function for antibody formation as indicated by increased antibody titer (Lovland et al., 2004). Heterophil's percentage was increased in all groups particularly in the $\mathrm{c}+\mathrm{ve}$ ones. Heterophilia, generally characterizes bacterial infections and conditions associated with tissue necrosis in birds (Campbell and Coles, 1986). A corticosteroid response associated with stress of a systemic disease or vaccination in birds has been found to reveal slight heterophilia and lymphopenia (Campbell, 2004a). In immunized groups, stress-induced lymphopenia may be masked by the prominent lymphocytosis. Monocytopenia is not considered a diagnostic problem and usually has no diagnostic significance (Campbell and Coles, 1986). Eosinophils decreased specially in $\mathrm{C}+$ ve groups and in TAC group. Eosinopenia can be a predictor of bacterial infection or it can be induced by any stressful condition resulting in release of glucocorticoids (Campbell and Coles, 1986).

Blood chemistry results showed increased serum TP, Alb and Glob values. Elevated serum protein in birds occurs with dehydration or if there is increase in globulins (Campbell and Coles, 1986 and Campbell, 1995). In the $\mathrm{C}+\mathrm{ve}$ groups these increases could be attributed to hemoconcentration as a result of diarrhea. In immunized groups, serum TP significantly increased particularly after the second dose of vaccination probably due to increased globulin concentration as a result of high-tittered antibody response to vaccination. Lovland et al., (2004) stated that vaccination of broiler breeder with candidate vaccines based on $C$. perfringens type $\mathrm{A}$ and type $\mathrm{C}$ toxoids results in a strong serum immunoglobulins levels particularly of type $\mathrm{G}$.

This approach is further supported by the result of $\mathrm{A} / \mathrm{G}$ ratio which was decreased in immunized birds probably due to hyperglobulinemia.

Regarding to results of serum ALT and AST activities as indicators of liver function, our data demonstrated that there was an increase in the serum activities of these enzymes despite the absence of gross hepatic lesions. Some elevation in serum ALT and AST has been found to be associated with glucocorticoid excess so stress associated with systemic illness can induce increased serum activities of these enzymes in chickens (Campbell and Coles, 1986). Some authors mentioned that there is a little serum ALT activity in normal chicken blood and ALT is not a useful diagnostic test for liver disease in birds, in addition serum AST is not liver specific in birds (Campbell, 2004b). Ivins et al., (1978) stated that a moderate increase of serum AST activity (two to four fold increase) is seen with soft tissue injury, whereas liver necrosis causes a more marked elevation. ALP significantly increased in the present study particularly in C + ve groups probably due to enteritis. In the chicken it was suggested that the intestinal isoenzyme of alkaline phosphatase makes the largest contribution to plasma ALP activity and is affected by intestinal disturbances and inappetance (Campbell, 2004b).

Although no renal lesions were reported in the present work, uric acid was increased. Uric acid is the end product of nitrogen metabolism and is the major nitrogenous component excreted by fowl (Campbell and Coles, 1986). Hyperuricemia in birds occurs with starvation, gout, massive tissue destruction, dehydration, reduced feed intake or absorption and renal disease (Campbell and Coles, 1986 and Campbell, 2004b). Various authors have suggested that the production of ammonia from urea by intestinal flora and the resultant excess ammonia absorption from large intestine can elevate serum uric acid (Anderson, 2002). Kaldhusdal and Hofshagen (1992) stated that focal intestinal ulceration would be expected to result in failure of nutrient absorption as well as permitting absorption of products of tissue necrosis materials present in the gut content that can elevate some serum parameters as urea.

Based on results of ELISA test, there was a gradual increase in antibody titer in the immunized groups particularly in association with the second dose of vaccination. Sera from broilers vaccinated with $C$. perfringens type AC had significantly higher antibody titers so that provided the best protective effect followed by 
toxoid A and finally toxoid C (Fig. 2). Further on challenging, birds immunized with TAC were provided with the greatest protection against challenge. Heier et al., (2001) established that flocks with high titres of maternal antibodies to alpha-toxin had lower mortality during the production period than flocks with low titres. Gobbi (2008) demonstrated significant higher levels of $C$. perfringens alpha toxin antibodies after vaccinating hens with $T A$ vaccine.

Cconclusion, the present data suggests some evidence that immuno prophylaxis by using $C$. perfringens toxoid vaccine may help reduce the incidence and severity of NE and seems to be an interesting and successful alternative for the control of the disease in broilers. Based on the clinicopathological data, all vaccination regimes used were found to be safe and well tolerated for broilers. No significant variation between both doses of vaccines in their negative impact on broilers was detected thus, booster doses of vaccines are recommended as it provides higher antibody titers. Toxoid AC is preferable as it provide the best protective effect followed by A and finally C. Further work is required to confirm the utility of maternal immunization with toxoid vaccines against $\mathrm{NE}$ and the effect of vaccines on egg production, fertility and hatchability under our environmental conditions.

\section{References}

Al-Sheikhly, F. and Al-Saieg, A. (1980): Role of coccidia in the occurrence of necrotic enteritis of chickens. Avian Dis., 24:324-333.

Anderson, D. B. (2002): Intestinal Microbes: When does normality change into a health and performance insult? The Elanco Global Enteritis Symp., 3-9.

Barker, I. K.; van Dreumel, A. A. and Palmer, N.C. (1993): The alimentary system. In: Pathology of domestic animals, Jubb, KVF; Kennedy, PC and Palmer N, 4th ed., Academic Press, Toronto, Canada.

Broussard, C.; Schrader, J.; Sweeney, D.; Jayappa, H. and Dimmick, S. (2008): Field efficacy of Netvax, a Clostridium perfringens type A toxoid breeder vaccine, in preventing mortality due to necrotic enteritis in broilers. Presentation at the $23^{\text {th }}$ Wrld. Poult. Cong. Brisbane, Australia.

Campbell, T.W. (1995): Avian Hematology And Cytology, $2^{\text {nd }}$ ed., Iowa state University, Press/Ames.

Campbell, T.W. (2004a): Hematology of birds. In: Veterinary hematology and clinical chemistry, Anna, M.T., Lippincott Williamas \& Wilkins, 351 West Camden Street, Baltimore, Maryland, 21201 USA

Campbell, T.W. (2004b): Clinical chemistry of birds. In: Veterinary hematology and clinical chemistry, Anna, M.T., Lippincott Williamas \& Wilkins, 351 West Camden Street, Baltimore, Maryland 21201 USA .

Campbell, T.W. and Coles, E.H. (1986): Avian Clinical Pathology. In: Veterinary Clinical Pathology, Coles, E.H., $4^{\text {th }}$ ed., W.B. Saunders Company, Philadelphia.
Connolly, A. (2001): Rising to the challenge of removing antibiotic growth promoters from feed and how specific oligosaccharides have led the way. Zootec. Inter. 5:44-49.

Ficken, M.D. and Wages, D.P. (1997): Necrotic Enteritis. In: Disease of Poultry, 10th ed. B.W. Calnex, editor. Iowa State University Press, Ames, Iowa pp. 261-264.

Gadalla, M. S.; Farrag, I.; El-Shahat, F.; El-Bendary, T. and Mostafa, R. (1969): Studies on polyvalent vaccine against some clostridial diseases in sheep. J. Vet. Sci., 6 (1): $1-14$.

Gobbi, L. (2008): Maternal immunization with Netvax against clinical and subclinical necrotic enteritis in broiler chickens. Presentation at the $23^{\text {th }}$ World's Poultry Congress in Brisbane, Australia.

Heier, B.T.; Lovland, A.; Soleim, K.B.; Kaldhusdal, M. and Jarp, J. (2001): A field study of naturally occurring specific antibodies against Clostridium perfringens Alpha toxin in Norwegian broiler flocks. Avian Dis., 45: 724-732.

Hemboldt, C. F. (1971): The pathology of necrotic enteritis in domestic fowl. Avian Dis., 775-780.

Hutchison, T. W. S. and Riddell, C. (1990): A study of hepatic lesions in broiler chickens at processing plants in Saskatchewan. Can. Vet. J., 31:20-25.

Ivins, G.K.; Weddle, G.D. and Halliwell, W.H. (1978): Hematology and Serum Chemistries in Birds of Prey. In: Zoo and Wild Animal Medicine, edited by Fowler, M.E. , W.B. Saunders Co., Philadelphia.

Jayappa, H.; Dimmick, S.; Ectenkamp, L.; Schrader, J.; Jia, W.; Sweeney, W.; Hofacre, C. and Wasmoen, T. (2005): Evaluation of passive protection in 3-week-old broiler chicks against necrotic enteritis caused by $\mathrm{C}$. perfringens type A isolate expressing alpha and beta-2 toxin. Presentation at the $54^{\text {th }}$ Western Poultry Disease Conference.

Kaldhusdal, M. and Hofshagen, M. (1992): Barley inclusion and avoparcin supplementation in broiler diets. 2 . Clinical, pathological, and bacteriological findings in a mild form of necrotic enteritis. Poult. Sci., 71(7):1145-1153.

Kaldhusdal, M. and Lovland, A. (2000): The economical impact of Clostridium perfringens is greater than anticipated. Wrld. Poult., 16: 50-51.

Kulkarni R. R.; Parreira V. R.; Sharif, S. and Prescott J. F. (2006): Clostridium perfringens antigens recognized by broiler chickens immune to necrotic enteritis. Clin. Vaccine Immunol., 13:1358-1362.

Kulkarni R. R.; Parreira V. R.; Sharif, S. and Prescott J. F. (2007): Immunization of broiler chickens against Clostridium perfringens-induced necrotic enteritis. Clin Vaccine Immunol., 14(9):1070-1077.

Lovland, A. and Kaldhusdal, M. (1999): Liver lesions seen at slaughter as an indicator of necrotic enteritis in broiler flocks. FEMS Immunol. Med. Microbiol., 24:345351.

Lovland, A. and Kaldhusdal, M. (2001): Severely impaired production performance in broiler flocks with high incidence of Clostridium perfringens-associated hepatitis. Avian Pathol., 30 (1):73-81.

Lovland, A.; Kaldhusal, M.; Redhead, K.; Skjerve, E. and Lillehaug, A. (2004): Maternal vaccination against subclinical necrotic enteritis in broilers. Avian Pathology 33 (1): 83-92.

McClane, B.A. (2001): The complex interactions between Clostridium perfringens enterotoxin and epithelial tight junctions. Toxicol., 39: 1781-91.

McReynolds, J. L; Byrd, J. A.; Anderson, R. C.; Moore, R. W.; Edrington, T. S.; Genovese, K. J.; Poole, T. L.; Kubena, L. F. and Nisbet, D. J. (2004): Evaluation 
of Immunosuppressants and Dietary Mechanisms in an Experimental Disease Model for Necrotic Enteritis. Poult. Sci., 83:1948-1952

Newman, L. and Ambrose, N. (2008): Canadian broiler performance using Netvax, a Clostridium perfringens type A toxoid for necrotic enteritis control under commercial production. Presentation at the $23^{\text {th }}$ World's Poultry Congress in Brisbane, Australia.

Nillo, L. (1980): Clostridium perfringens in animal disease: A review of current knowledge. Can. Vet. J., 21:141-148.

Onderka, D. K.; Langevin, C. C. and Hanson, J. A. (1990): Fibrosing cholehepatitis in broiler chickens induced by bile duct ligations or inoculation of Clostridium perfringens. Can. J. Vet. Res., 54:285-290.

Parish, W. E. (1961): Necrotic enteritis in the fowl. III. The experimental disease. J. Comp. Pathol., 71:405-413.

Riddell, C. and Kong, XM (1992): The influence of diet on necrotic enteritis in broiler chickens. Avian Dis., 36:469-
503.

Schrader, J.; Broussard, C.; Hansen, J.; Dierks, L.; Oetting, A. and Petersen, G. (2008): Association of Clostridium perfringens type A alpha-toxin with lesions of necrotic enteritis evaluated by monoclonal antibody test strips and immunohistochemistry. Presentation at the $23^{\text {th }}$ World's Poultry Congress in Brisbane, Australia.

Thompson, D. R.; Parreira V. R.; Kulkarni, R. R. and Prescott, J. F. (2006): Live attenuated vaccine-based control of necrotic enteritis of broiler chickens. Vet. Microbiol., 113:25-34.

Vander Sluis, W. (2000): Clostridial enteritis is an often underestimated problem. Wrld. Poult., 16: 42-43.

Van Immerseel, F.; De Buck, J.; Pasmans, F.; Huyghebaert, G.; Haesebrouck, F. and Ducatelle, R. (2004): Clostridium perfringens in poultry: an emerging threat for animal and public health. Avian Pathol., 33 (6): 537-549.

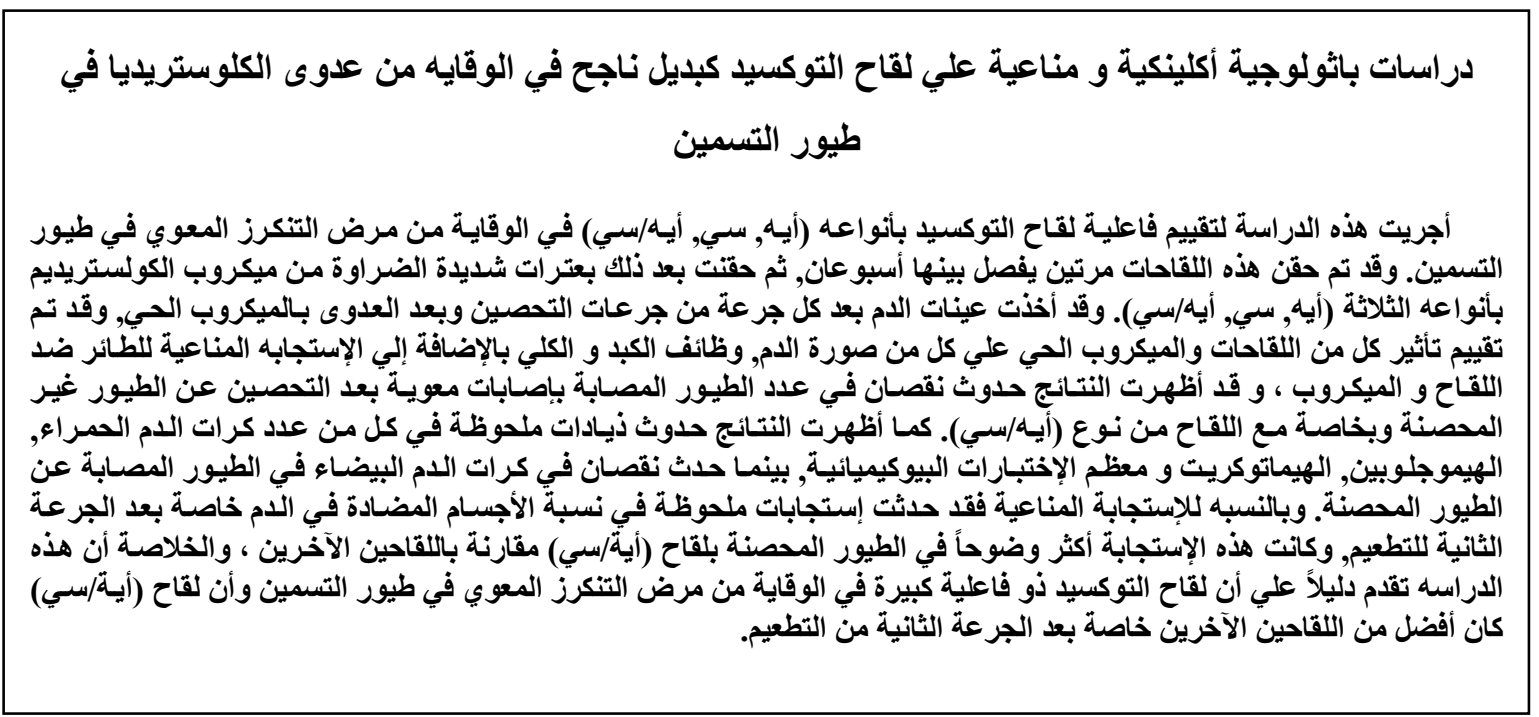

